\title{
Mesoporous Carbon Production by Nanocasting Technique Using Boehmite as a Template
}

\author{
María Ortega-Franqueza, Svetlana Ivanova $(\mathbb{D}$, María Isabel Domínguez $(\mathbb{D})$ and Miguel Ángel Centeno *(i) \\ Instituto de Ciencia de Materiales de Sevilla and Departamento de Química Inorgánica, Centro Mixto \\ CSIC-Universidad de Sevilla, Av. Américo Vespucio 49, 41092 Sevilla, Spain; \\ ortegafranqueza@gmail.com (M.O.-F.); sivanova@us.es (S.I.); mdominguez1@us.es (M.I.D.) \\ * Correspondence: centeno@icmse.csic.es; Tel.: +34-954489543
}

Citation: Ortega-Franqueza, M.; Ivanova, S.; Domínguez, M.I.; Centeno, M.Á. Mesoporous Carbon Production by Nanocasting Technique Using Boehmite as a Template. Catalysts 2021, 11, 1132. https://doi.org/10.3390/catal11091132

Academic Editors:

Hamidreza Arandiyan and Leonarda Francesca Liotta

Received: 4 August 2021

Accepted: 19 September 2021

Published: 21 September 2021

Publisher's Note: MDPI stays neutral with regard to jurisdictional claims in published maps and institutional affiliations.

Copyright: (C) 2021 by the authors Licensee MDPI, Basel, Switzerland. This article is an open access article distributed under the terms and conditions of the Creative Commons Attribution (CC BY) license (https:/ / creativecommons.org/licenses/by/ $4.0 /)$.

\begin{abstract}
A series of mesoporous carbonaceous materials were synthesized by the nanocasting technique using boehmite as a template and glucose as a carbon precursor. After pyrolysis and template removal, the resulting material is a mesoporous carbon that can be additionally doped with $\mathrm{N}, \mathrm{B}$ and $\mathrm{K}$ during prepyrolysis impregnation. In addition, the influence of doping on the morphology, crystallinity and stability of the synthesized carbons was studied using X-ray diffraction, nitrogen physisorption, thermogravimetry, Raman and IR spectroscopy and transmission electron microscopy. While the nanocasting process is effective for the formation of mesopores, $\mathrm{KOH}$ and urea do not modify the textural properties of carbon. The use of $\mathrm{H}_{3} \mathrm{PO}_{4}$ as a dopant, however, led to the formation of an $\mathrm{AlPO}_{4}$ compound and resulted in a solid with a lower specific surface area and higher microporosity. All doped solids present higher thermal stability as a positive effect of the introduction of heteroatoms to the carbon skeleton. The phosphorus-doped sample has better oxidation resistance, with a combustion temperature $120-150{ }^{\circ} \mathrm{C}$ higher than those observed for the other materials.
\end{abstract}

Keywords: nanocasting; mesoporous carbons; doping; boehmite; glucose

\section{Introduction}

Mesoporous carbons are materials with a continuous carbon skeleton with a pore size within the range of 2 to $50 \mathrm{~nm}$ [1]. These materials present very interesting properties such as a large surface area, adjustable framework, tunable pore size, high resistance to corrosion and high mechanical and thermal stability. These features, along with their appreciable electron conductivity and relative chemical inertness, make these materials very useful in various fields such as adsorption, biotechnology, energy storage, sensing applications and in catalysis as catalytic supports or catalysts $[2,3]$. When obtained from waste biomass (a renewable and low-cost source), mesoporous carbons are considered environmentally benign and cost competitive to other supports or heterogeneous catalysts [4]. Mesoporous carbons can be obtained by different processes such as carbonization and activation of organic precursors or by direct synthesis $[5,6]$. More complex and interesting carbon-based structures can also be obtained using new methods such as additive manufacturing and high-temperature pyrolysis procedures, which allow the formation of pyrolytic carbon micropillars with nanosized voids and associated nanolattices with improved mechanical properties and large deformability with great potential for energy storage applications [7-9].

However, molding or templating is one of the most powerful techniques in which highly structured porous networks are obtained using either solids (exotemplating or hard templating) or molecules (endotemplating or soft templating) as templates to obtain inverse carbon replicas. This method has the advantage of easy control of particle morphology and pore size by selecting the used template [10]. On the other hand, hard templating, also known as nanocasting, is a versatile, cheap and suitable way for industrial applications. The mold that acts as a 'template' is impregnated with a carbon precursor 
and then processed and submitted to chemical treatments to obtain an inverse replica of the initial mold.

Rigid inorganic solids, such as mesoporous zeolites, aluminas and lamellar solids such as hydrotalcites, can be used as templates. The mesostructure and pore surface of the template are decisive for the infiltration of the precursor and favored by its rigid replica's structure control [5].

The template channels are infiltrated with an appropriate carbon precursor, commonly a sugar, such as sucrose or glucose, that is in situ converted by carbonization or pyrolysis to carbon which within the template structure appears as a continuous carbon network. Once the precursor has replicated the negative of the template, the target materials are received after template removal $[2,3,11]$.

Doping the carbonaceous structure with specific heteroatoms can increase its thermal, mechanical and structural stability while improving the selectivity, activity and durability of these materials in catalytic reactions $[12,13]$. Heteroatoms such N, B and P have been classically used for this purpose, as they can generate superficial defect sites that break carbon electroneutrality, improving this way the performance of the carbonaceous material. For example, P- or B-doped mesoporous carbons present better catalytic properties in direct dehydrogenation of propane (higher propane conversion and propene selectivity) than undoped carbon due to the increase in the population of the main active sites (carbonyl/quinone groups) [14]. On the other hand, $\mathrm{N}$-doped carbon catalysts speed up the dissociative adsorption of oxygen molecules, decreasing the activation energy for oxidative dehydrogenation $[15,16]$. Carbon activation achieved by doping with potassium is especially interesting. This element is intercalated between the graphite sheets in their cationic form, $\mathrm{K}^{+}$, increasing the specific surface of these materials. It also manages to increase graphite conductivity by more than one order of magnitude, achieving superconductivity at very low temperatures in crystalline graphite. Finally, and because of its low reduction potential, potassium is easily reduced to its neutral form during all heating stages which is coupled with the oxidation of $C[17,18]$. The main strategies described in the literature for the production of doped carbons are based on the use of a precursor rich in the desired element, included either directly in the synthesis process or in the post-treatment process after the synthesis of the carbonaceous material [19-21].

Boehmite is a mesoporous aluminum oxyhydroxide (AlOOH) that can be used as a template in nanocasting processes. Orthorhombic boehmite minerals (space group $\mathrm{Cmcm}$ ) crystallize in a two-dimensional structure, with layers of edge-shared $\mathrm{AlO}_{4}(\mathrm{OH})_{2}$ octahedra linked by hydrogen bonds (Figure 1) [22-24]. Boehmite is a cheap template and can be prepared using a simple sol-gel method.
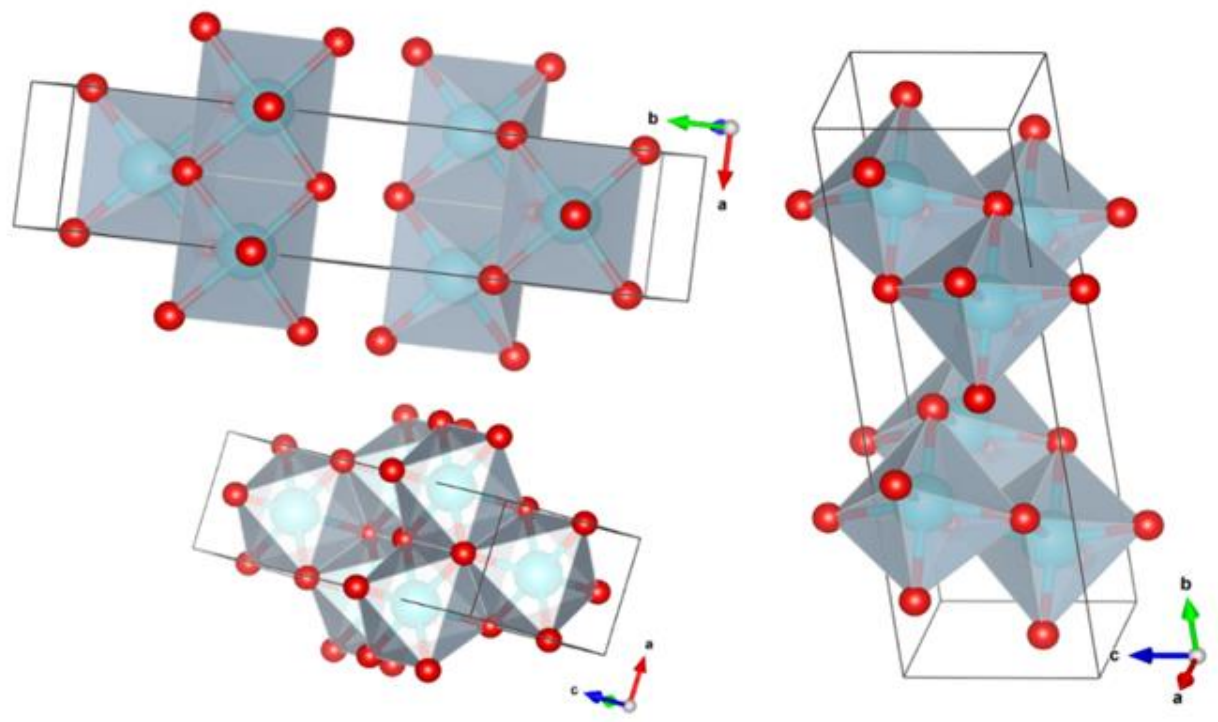

Figure 1. Crystal structure of boehmite. Crystallographic Open Database ID: 9012253. 
The pyrolysis treatment to which the template is subjected after infiltration with the carbon source could cause boehmite transformation into different transitional alumina phases, depending on the used temperature and atmosphere. In the temperature range generally used for the pyrolysis of organic matter to obtain carbon materials, a gammaalumina phase is produced. Gamma-alumina, $\gamma-\mathrm{Al}_{2} \mathrm{O}_{3}$, is transitional metastable alumina in the temperature range of $500-850{ }^{\circ} \mathrm{C}$ [25]. The structure of $\gamma-\mathrm{Al}_{2} \mathrm{O}_{3}$ is traditionally considered a cubic defective spinel in which the oxygen atoms are arranged in a cubic close packing (face-centered cubic (fcc)), and the Al atoms occupy the octahedral and tetrahedral sites with existing cationic vacancies that maintain the electric neutrality [26,27]. It is also a mesoporous oxide widely used as catalytic support due to its suitable surface and textural properties.

As far as we know, boehmite has not been used before as a template in the nanocasting process to obtain mesoporous carbon. However, some studies have been published dedicated to obtaining carbon nanotubes using anodic aluminum oxide (AAO) as a template [28-30].

Taking into account all described above, the objective of this work is to explore the use of boehmite as a template to obtain mesoporous carbons from biomass by the nanocasting method and to study the influence of different dopants on carbon structure and textural properties. The adopted strategy consists of using boehmite as a template, glucose as a carbon precursor (glucose) and the incorporation of different additives $\left(\mathrm{KOH}, \mathrm{H}_{3} \mathrm{PO}_{4}\right.$ and urea as a source of $\mathrm{K}, \mathrm{P}$ and $\mathrm{N}$, respectively) during the synthesis procedure. Glucose was selected as a carbon precursor, being a molecule representative of renewable vegetal lignocellulosic biomass as its main component [31].

\section{Results and Discussion}

A detailed description of doped/undoped mesoporous carbon preparation is provided in Section 3.

Figure 2 shows $\mathrm{X}$-ray diffractograms of the pyrolyzed samples before template removal. The pyrolysis process induces the transformation of the boehmite crystalline phase (AlOOH) to $\gamma-\mathrm{Al}_{2} \mathrm{O}_{3}$ (JCPDS: 00-010-0425). This transformation is consistent with the used temperature $\left(70{ }^{\circ} \mathrm{C}\right)$ [25]. Only in the case of the sample impregnated with phosphoric acid does the formation of a new crystalline phase (aluminum phosphate $\left(\mathrm{AlPO}_{4}\right)$, JCPDS: 00-051-1674) occur after the reaction between additive and template. In all samples, carbon diffractions are not clearly discernible due to their overlap with those of the template.

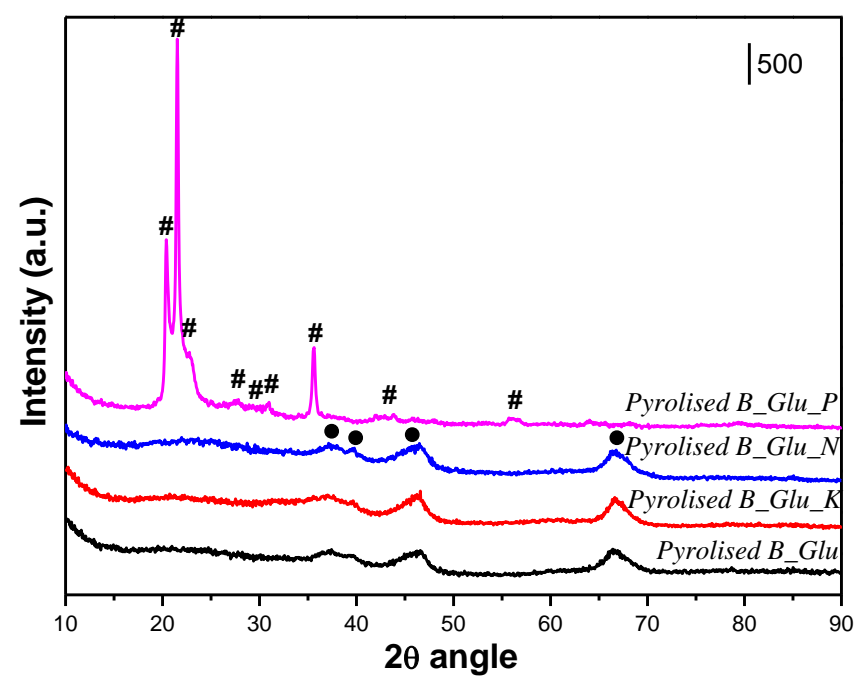

Figure 2. Pyrolyzed samples diffractograms (\# $\mathrm{AlPO}_{4}, \bullet \gamma$-alumina).

According to the $\mathrm{XRD}$ results, the materials generated after pyrolysis can be considered template-carbon hybrids $\left(\mathrm{AlPO}_{4}-\mathrm{C}\right.$ in the case of the sample treated with phosphoric 
acid and $\gamma-\mathrm{Al}_{2} \mathrm{O}_{3}-\mathrm{C}$ for the rest of the series). However, while not the objective of the present paper, the hybrid materials could be of high potential interest, as carbonaceous hybrid materials with nanocomposites is an emerging field with a large variety of possible applications in different scientific and technical fields, such as catalysis, electrochemistry, absorption, sensors, etc. [32,33]. Additionally, our hybrids are obtained in an economical and sustainable way.

The effectiveness of successive template removal treatments, i.e., dissolution stages (up to four), was followed by XRD. As an example, Figure 3A shows an evolution of the X-ray diffractograms of the pyrolyzed B_Glu sample after each dissolution stage. It can be seen how the different dissolution stages lead to more effective removal of the template, confirmed by the appearance of characteristic diffractions of the carbonaceous material visible in the final solid. After the third dissolution stage, a new crystalline phase appears, with a peak at $2 \theta \approx 18^{\circ}$, which could be assigned to a silicate, perhaps from contamination produced by the glass containers used for the template dilution processes.
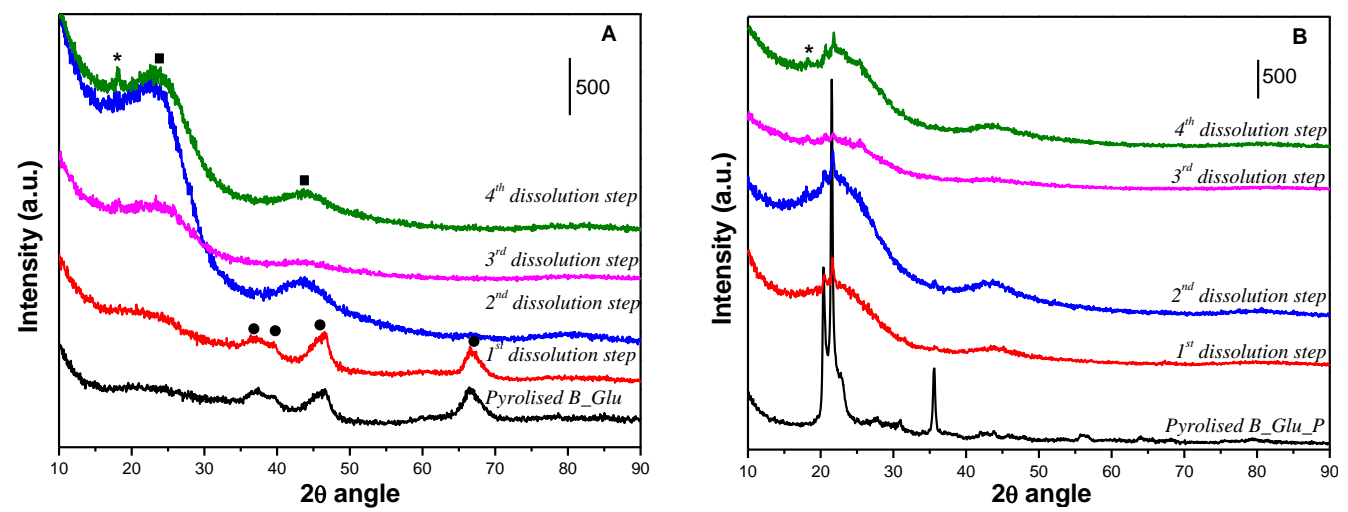

Figure 3. Evolution of X-ray diffractograms of (A) pyrolyzed $B \_G l u$ sample and (B) pyrolyzed $B \_G l u \_P$ sample after each stage of template dissolution ( $\mathbf{\square}$ carbon, $\bullet \gamma$-alumina, ${ }^{*}$ silicate).

Similar results were obtained for the pyrolyzed $B \_G l u \_K$ and $B \_G l u \_N$ samples (Figures S1 and S2), evidencing that the template removal treatments have a similar effect in such materials.

In the case of the pyrolyzed $B \_G l u_{-} P$ sample, complete elimination of the $\mathrm{AlPO}_{4}$ phase was not achieved after four stages of dissolution, confirmed by the visible diffractions corresponding to that compound (Figure 3B).

Figure 4 shows diffractograms of the final carbons obtained after the full template dissolution treatment. In all cases, reflections at $2 \theta \approx 25^{\circ}, 44^{\circ}$ and $80^{\circ}$ are observed, corresponding, respectively, to the families of planes (002), (100) and (110) of graphitic carbon. Diffraction of (002) planes is attributed to the structural packing of the aromatic layers through van der Waals forces, while (100) and (110) signals arise from the aromatic structures in the plane [34,35].

The intensity of the (002) peak is related to the degree of graphitic crystallinity in such a way that wide and low-intensity peaks indicate a low order at short range of the graphite carbon sheets organization, while sharp and narrow peaks correspond to highly crystalline carbons with a high degree of order at long range [34-36].

To evaluate the degree of crystallinity of the obtained carbons, the crystallite height $(L c)$ and crystallite diameter $(L a)$ parameters were calculated. The magnitudes of these parameters determine the sizes of the crystals within the carbon sample [34,35,37]. An increase in those parameters an increased graphitization of the carbon. Additionally, the interlayer spacing $\left(d_{002}\right)$, the number of aromatic layers per carbon crystallite $\left(N_{\text {ave }}\right)$ and the $R$ value, considered as the empirical graphical ratio of the (002) XRD peak intensity relative to the background at the same scattering angle, have been estimated [38]. All these values are summarized in Table 1. 


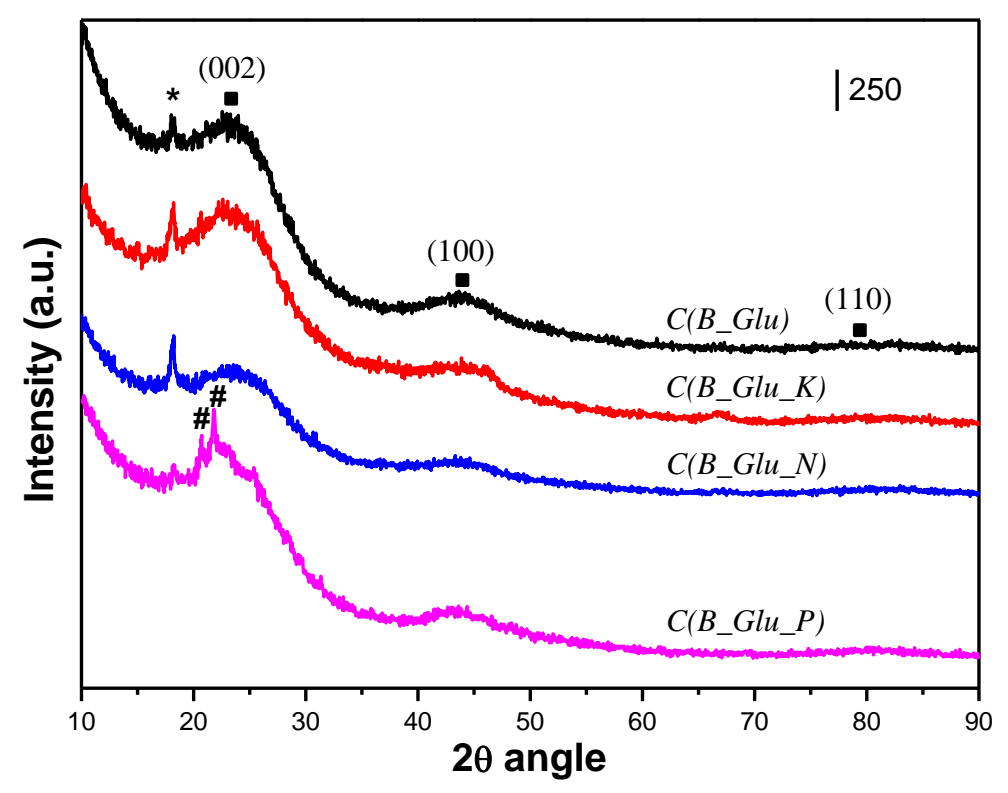

Figure 4. Diffractograms of the synthesized carbons ( $\mathbf{\square}$ carbon, \# $\mathrm{AlPO}_{4},{ }^{*}$ silicate).

Table 1. Structural parameters for the synthesized carbons.

\begin{tabular}{cccccc}
\hline Sample & $\boldsymbol{L}_{\boldsymbol{c}}(\AA)$ & $\boldsymbol{L}_{\boldsymbol{a}}(\AA)$ & $\boldsymbol{R}$ & $\boldsymbol{d}_{\mathbf{0 0 2}}$ & $\boldsymbol{N}_{\text {ave }}$ \\
\hline C(B_Glu $)$ & 14 & 29 & 1.56 & 3.63144 & 5 \\
C(B_Glu_K $)$ & 10 & 29 & 1.7 & 3.72021 & 4 \\
C(B_Glu_N $)$ & 10 & 29 & 1.6 & 3.6451 & 4 \\
C(B_Glu_P $)$ & 14 & 24 & 1.64 & 3.79856 & 5 \\
\hline
\end{tabular}

Insignificant differences are observed within the synthesized series of materials, pointing to a similar degree of crystallinity for all samples. While the presence of dopants such as $\mathrm{N}$ and $\mathrm{K}$ results in a lower value of the $L_{c}$ parameter and, therefore, a decrease in the average number of graphenic layers $\left(N_{\text {ave }}\right)$, the $C\left(B_{-} G l u_{-} P\right)$ sample remains similar to the undoped carbon.

Figure 5 presents $\mathrm{N}_{2}$ adsorption isotherms of the obtained carbons. According to IUPAC [39], all present type IV isotherms with an $\mathrm{H} 3$ hysteresis loop in the $0.4<P / P_{0}<0.9$ range, indicating a mesoporous character consisting of aggregates of particles with slit-shaped pores and a nonhomogeneous distribution in shape and/or size [40-42]. A low microporosity proportion is suggested by the small adsorption at very low pressures $\left(P / P_{0}<0,1\right)[41]$, and the final materials can be described as micromesoporous carbons $[39,43]$.

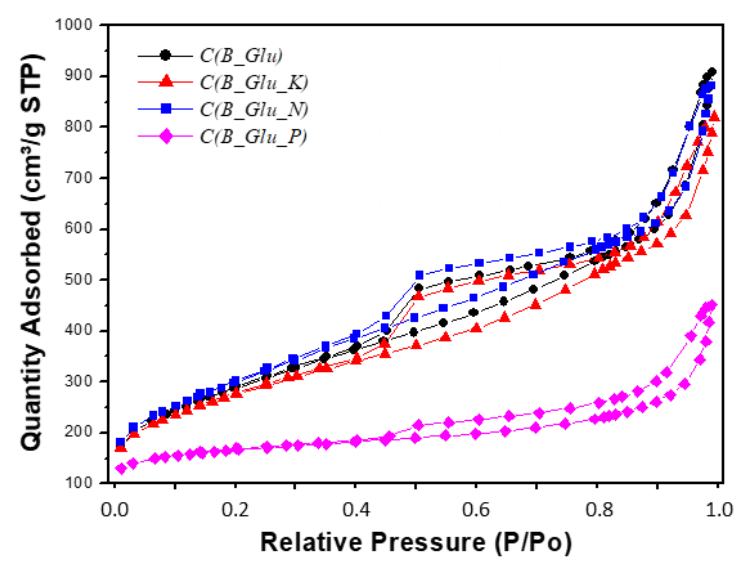

Figure 5. $\mathrm{N}_{2}$ isotherms of the synthesized carbons. 
Pore volumes were calculated from the desorption branch using the BJH method. According to the pore size distribution and assuming cylindrical pores (Figure 6), all samples present dominant mesoporosity with the main pores around $4 \mathrm{~nm}$ in diameter and a certain total volume fraction due to larger pores $(20-50 \mathrm{~nm})$ and micropores.

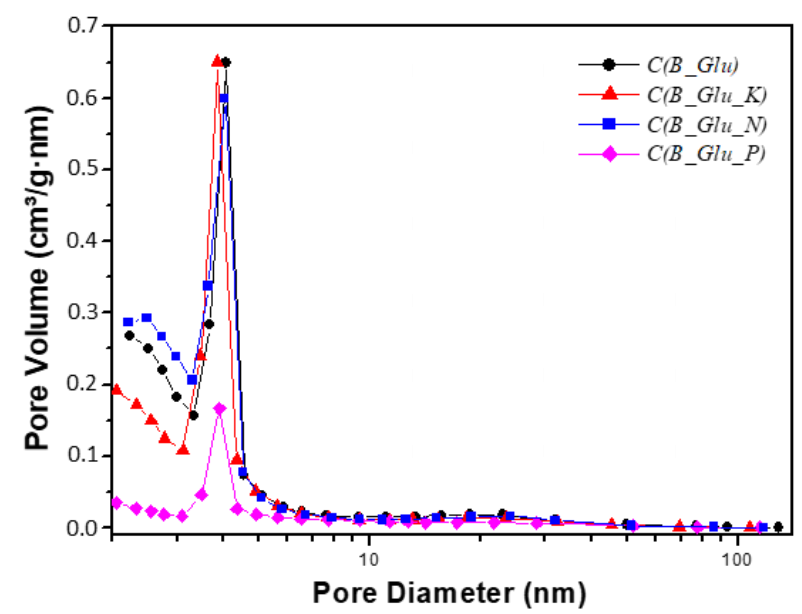

Figure 6. Pore size distribution of the synthesized carbons (BJH desorption $\mathrm{dV} / \mathrm{dD}$ pore volume).

Table 2 summarizes the textural properties of the synthesized carbons. All samples have high BET surface areas (typically around $1000 \mathrm{~m}^{2} / \mathrm{g}$ ) and pore volume (higher than $1,2 \mathrm{~cm}^{3} / \mathrm{g}$ ) characteristics for mostly mesoporous carbons [41]), which makes them suitable for possible applications as catalytic supports or absorbents. A revision of some uses of templated mesoporous carbons can be found in Ref. [3]. The most suitable application will depend not only on the carbon's pore characteristics but also on the presence of surface functional groups, which, as we will show later, is also dependent on the used dopant agent. In any case, the textural characteristics of our carbons are similar to those reported for mesoporous carbons acting as efficient supercapacitors as catalysts or as adsorbents of organic molecules and metal ions. Saygili et al. [44] reported that activated carbons produced from tomato wastes in different pyrolysis conditions with a maximal BET area of $1093 \mathrm{~m}^{2} / \mathrm{g}$, a total pore volume of $1569 \mathrm{~cm}^{3} / \mathrm{g}$ and a mean diameter of $5.92 \mathrm{~nm}$ can successfully be used as a sorbent to remove cationic (methylene blue) and anionic (metanil yellow) dyes from aqueous solutions. Santos et al. [45] reported the beneficial effect of the mesoporosity of carbon materials on palladium catalyst activity in the reaction of clean hydrogen production via formic acid decomposition. A pore volume of $1 \mathrm{~cm}^{3} / \mathrm{g}$ and pore sizes of around $2.7 \mathrm{~nm}$ are found optimal for maximal hydrogen productivity.

Table 2. Textural properties of the obtained carbons.

\begin{tabular}{ccccc}
\hline Sample & $\begin{array}{c}\text { BET } \\
\mathbf{m}^{\mathbf{2}} / \mathbf{g}\end{array}$ & $\begin{array}{c}\text { Micropore } \\
\text { \% }\end{array}$ & $\begin{array}{c}\text { BJH desor } \\
\text { Pore vol. } \mathbf{c m}^{\mathbf{3}} / \mathbf{g}\end{array}$ & $\begin{array}{c}\text { 4V/A by BET } \\
\text { Pore diam. } \mathbf{~ n m}\end{array}$ \\
\hline C(B_Glu) & 1038 & 5.9 & 1.50 & 4.8 \\
C(B_Glu_K $)$ & 990 & 11.2 & 1.26 & 4.5 \\
C(B_Glu_N) & 1078 & 2.5 & 1.47 & 4.5 \\
C(B_Glu_P $)$ & 569 & 57.3 & 0.54 & 3.7 \\
\hline
\end{tabular}

The introduction of heteroatoms and potassium does not seem to have a great influence on the textural properties of the materials, except in the case of the $C\left(B_{-} G l u_{-} P\right)$ sample. The latter presents different textural properties from the rest, such as a much smaller surface area, lower mesoporosity and a higher percentage of micropores. This is due to the formation of crystalline microporous aluminum phosphate, $\mathrm{AlPO}_{4}$, that results in less mesoporous carbon after pyrolysis. This fact confirms the chief role of template porosity for developing carbon replica textural properties. 
Table 3 shows the most relevant data of the thermogravimetric analysis of the carbonaceous materials after the first template dissolution stage and after its complete elimination.

Table 3. Thermal analysis results.

\begin{tabular}{ccccc}
\hline Sample & $\begin{array}{c}\text { Water loss } \\
\mathbf{T}\left({ }^{\circ} \mathbf{C}\right)\end{array}$ & Water loss wt \% & $\begin{array}{c}\text { Combustion } \\
\mathbf{T}\left({ }^{\circ} \mathbf{C}\right)\end{array}$ & $\begin{array}{c}\text { Ashes } \\
\text { wt } \%\end{array}$ \\
\hline B_Glu $(1)$ & 63 & 6.5 & 451 & 45.3 \\
C(B_Glu) & 61 & 257 & 342 & 6.8 \\
B_Glu_K $(1)$ & 66 & 6.2 & 457 & 52.2 \\
C(B_Glu_K) & 43 & 13.4 & 357 & 4.8 \\
B_Glu_N $(1)$ & 65 & 6.5 & 462 & 41.0 \\
C(B_Glu_N) & 54 & 12.0 & 363 & 7.3 \\
B_Glu_P $(1)$ & 55 & 8.1 & 484 & 13.0 \\
C(B_Glu_P) & 51 & 12.7 & 482 & 10.2 \\
\hline
\end{tabular}

(1) After the first dissolution step

In general, two processes of weight loss are observed: one at low temperature (around $50{ }^{\circ} \mathrm{C}$ ) ascribed to the loss of adsorbed water and another at higher temperatures due to the combustion of the carbonaceous skeleton. The percentage of weight remaining after combustion (ashes) is related to the mineral content of the sample, indicative of template leftovers. Figure 7 shows, as an example, graphs corresponding to the B_Glu sample, while Figures S3-S5 correspond to the other samples.

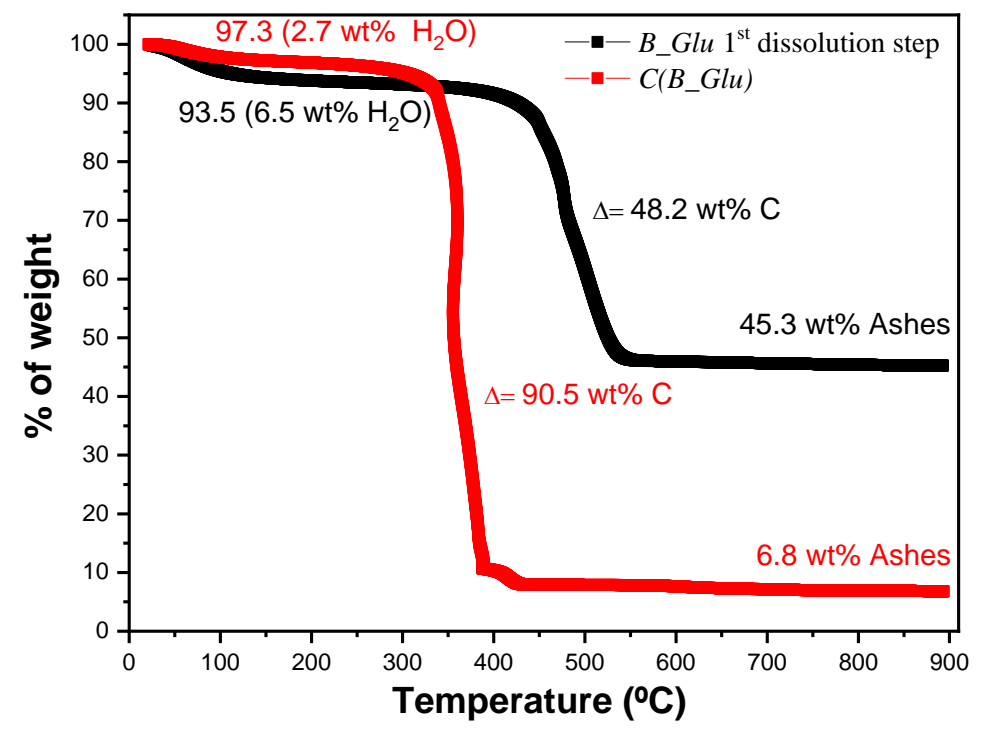

Figure 7. Thermal analysis for samples B_Glu (after the first template dissolution step) and C(B_Glu).

After the first dissolution stage, the amount of ashes is much higher than that of the final carbons, confirming the presence of a higher template proportion. Percentages of ashes in the final materials (after the complete dissolution process) are considerably reduced, demonstrating the effectiveness of the template removal process. Only for the $B \_G l u \_P$ sample is the amount of ashes similar after the first and the final dissolution stages. This must be related to the formation of an $\mathrm{AlPO}_{4}$ phase, not fully removed with the dissolution treatment, as evidenced by XRD (Figures 3B and 4).

Comparing the results for the final carbons (Figure 8 and Table 3), it is clear that $C\left(B \_G l u\right)$ carbon has a lower capacity to retain physisorbed water than doped carbons, which is evidenced by the smallest loss of weight at low temperatures ( $3 \mathrm{wt} \% \mathrm{vs} . \sim 13 \mathrm{wt} \%$ ). This fact points to a higher hydrophilic character for all doped samples, most probably related to a higher functionalization degree. 


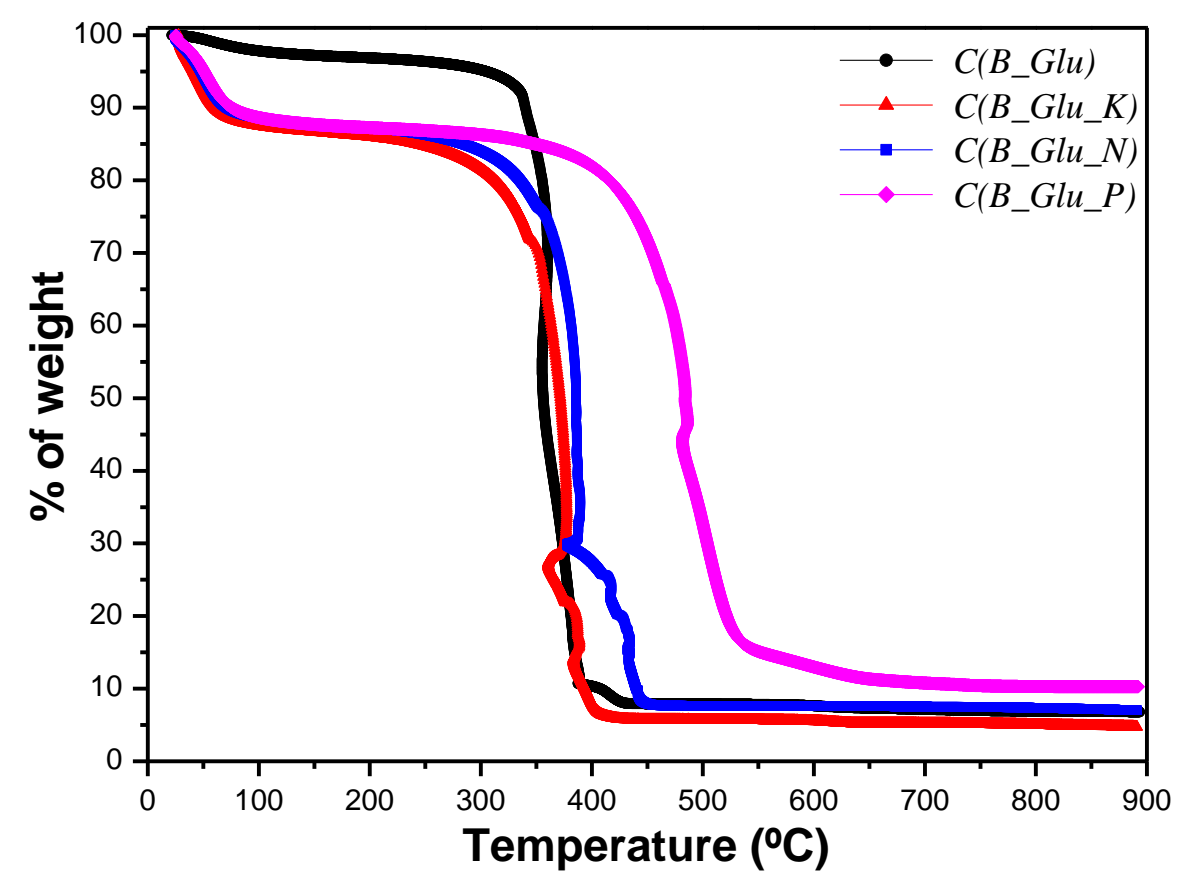

Figure 8. Thermal analysis for the obtained carbons.

Taking into account the combustion temperature of the carbonaceous skeleton (Table 3), the thermal resistance of the obtained carbons can be deduced. The following order of thermal resistance can be established: $C\left(B \_G l u \_P\right)>C\left(B \_G l u \_N\right)>C\left(B \_G l u \_K\right)>C\left(B \_G l u\right)$. All doped solids have higher thermal stability than their undoped homologs, showing the positive effect of heteroatom introduction and suggesting that all doped samples will be more difficult to oxidize. This must be also related to the differences in crystallinity, structural disorder, concentration of defects and edge plane sites exposition [46,47], with all doped samples presenting less disorder than undoped carbon. In any case, the differences are small among these three samples, as stated for XRD (Table 1 and Figure 4) and Raman (see later) analysis. The superior thermal stability of the phosphorus-doped sample in comparison to all other materials $\left(120-150{ }^{\circ} \mathrm{C}\right.$ higher) should also be mentioned, this effect being attributed to the presence of $\mathrm{AlPO}_{4}$.

Raman spectra of the prepared carbons in the first-order region $\left(1800-1100 \mathrm{~cm}^{-1}\right)$ are shown in Figure 9. Two bands are clearly visible: one more intense around $1600 \mathrm{~cm}^{-1}$, known as the G-band, characteristic of $\mathrm{sp}^{2} \mathrm{C}$ hybridization and related to the degree of graphitization; and another wide band around $1300 \mathrm{~cm}^{-1}$, known as the D-band, attributed to the presence of structural defects, partially disordered structures and $\mathrm{sp}^{3}$ hybridization of carbon. The estimation of the intensity ratio between both D- and G-bands (D/G ratio) is generally used to evaluate the disordered character of carbonaceous materials $[38,48,49]$. All prepared samples present similar D/G ratios (Table 4), characteristic of medium-grade disordered carbons [50]. Detailed analysis of the D/G ratios indicates that, except for the $C\left(B \_G l u \_P\right)$ sample, the doped carbons present slightly higher $D / G$ values, indicating mild modifications of the disorder degree, which could be related to the observed changes in the combustion temperature and water adsorption capacity (Table 3). 


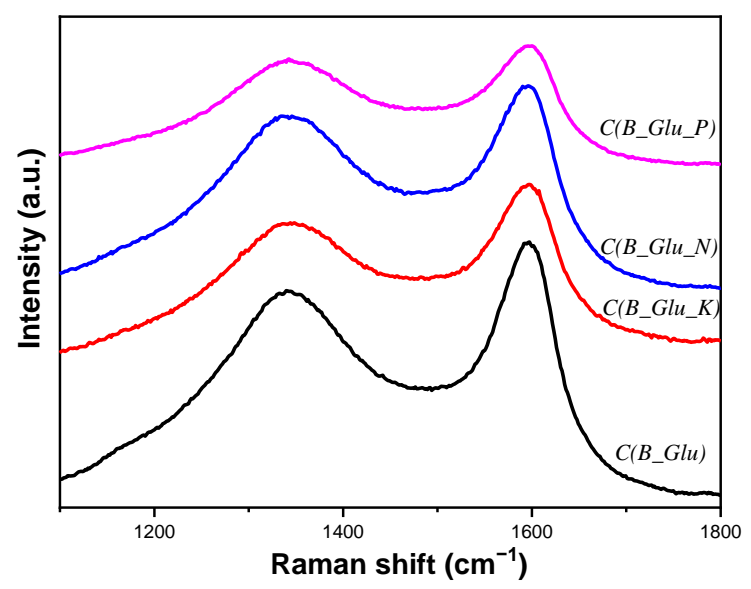

Figure 9. Raman spectra for the synthetized carbons.

Table 4. D/G intensity ratios for the obtained carbons.

\begin{tabular}{cc}
\hline Sample & D/G ratio \\
\hline C(B_Glu $)$ & 0.84 \\
$C\left(B \_G l u \_K\right)$ & 0.85 \\
C(B_Glu_N $)$ & 0.89 \\
C(B_Glu_P $)$ & 0.82 \\
\hline
\end{tabular}

Infrared studies evidence the similarity of the surface functionalities and carbonaceous structure of the obtained carbons (Figure 10). In addition to aliphatic C-C $\left(1460 \mathrm{~cm}^{-1}\right)$, $\mathrm{C}-\mathrm{H}\left(2800-3000 \mathrm{~cm}^{-1}\right)$ and aromatic $\mathrm{C}=\mathrm{C}\left(1605 \mathrm{~cm}^{-1}\right)$ and $\mathrm{C}-\mathrm{H}\left(3060 \mathrm{~cm}^{-1}\right.$ and group of bands at $660-910 \mathrm{~cm}^{-1}$ ) bonds, bands characteristic of oxygenated functionalities are also visible: $\mathrm{C}=\mathrm{O}\left(1725 \mathrm{~cm}^{-1}\right)$ and $\mathrm{C}-\mathrm{O}\left(1110-1300 \mathrm{~cm}^{-1}\right)$. The functionalization of the surface is also demonstrated by the wide band observed at around $3400 \mathrm{~cm}^{-1}$ due to O-H stretching of surface-adsorbed water. No bands due to the oxidic template are envisaged, demonstrating its complete removal. Only the $C\left(B_{-} G l u-P\right)$ sample shows small changes in the $1100-1000 \mathrm{~cm}^{-1}$ region, related to the existence of some traces of $\mathrm{AlPO}_{4}$, as $\mathrm{P}-\mathrm{O}$ and $\mathrm{Al}-\mathrm{O}$ stretching vibrations have been described to appear in this region [50].

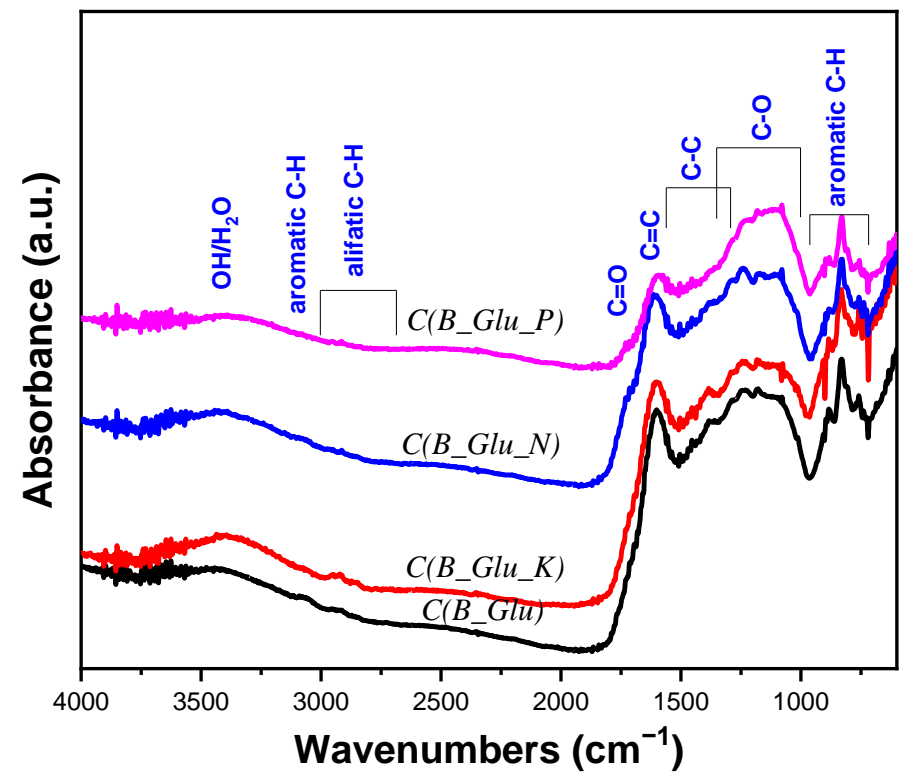

Figure 10. DRIFTS spectra of obtained carbons. 
The morphology, homogeneity and elemental chemical composition of the obtained solids were studied by TEM (Figures 11 and 12). The carbons do not present a hierarchical structure but a high degree of porosity, with pores within the mesoporosity order originated by the effective nanocasting process. Again, the $C\left(B \_G l u \_P\right)$ sample presents a different structure, and two regions can be differentiated: one composed of several very thin sheets and more open porosity (Region I, marked in red) and the other more similar to that observed for all other samples (Region II, marked in yellow).
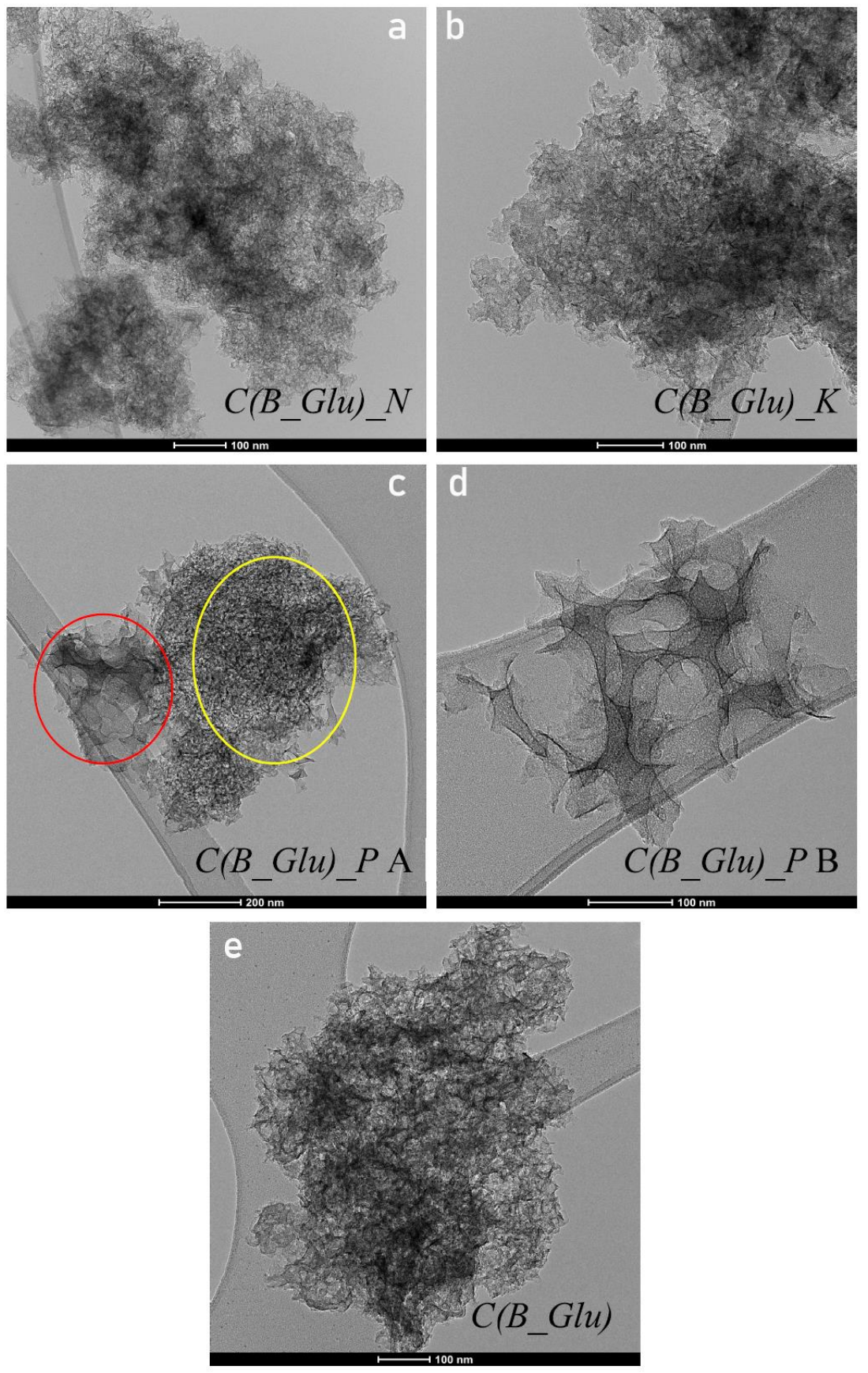

Figure 11. Selected TEM micrographs of the obtained carbons. (a) C(B_Glu)_N; (b) C(B_Glu)_K; (c) C(B_Glu)_P A; (d) C(B_Glu)_P B; (e) C(B_Glu). 
(a)

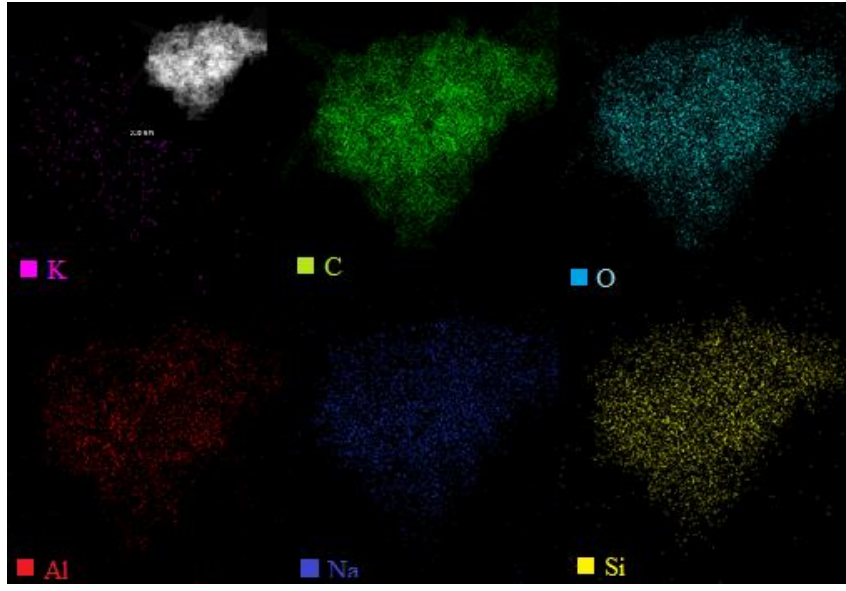

$C\left(B \_G l u \_K\right)$

(b)

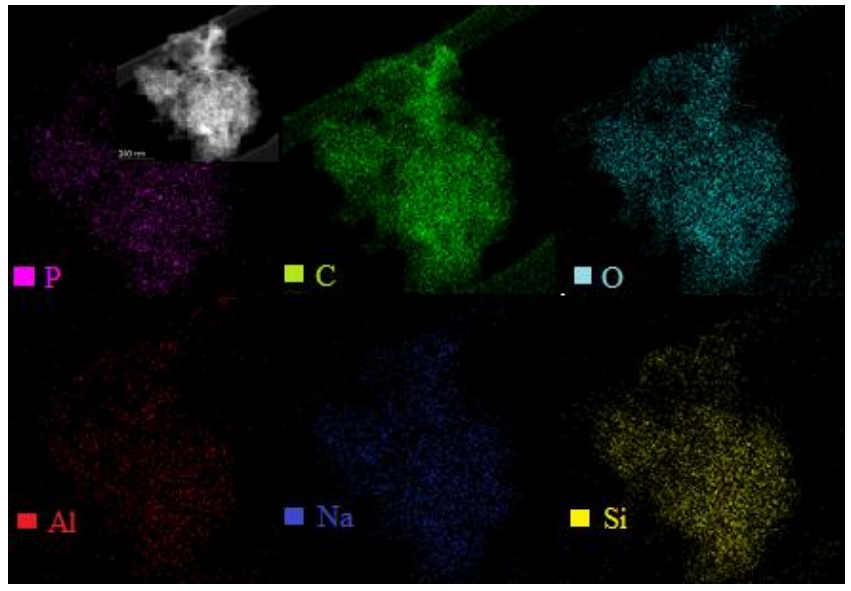

$$
C\left(B_{-} G l u_{-} P\right)
$$

Figure 12. Mappings for (a) $C\left(B_{-} G l u_{-} K\right)$ and $(\mathbf{b}) C\left(B_{-} G l u_{-} P\right)$.

Regarding the elemental composition of the materials, EDS compositional mappings for $C\left(B \_G l u \_K\right)$ and $C\left(B \_G l u \_P\right)$ are compared in Figure 12 (the other samples are summarized in Figures S6 and S7). Average EDS composition values are depicted in Table 5.

Table 5. EDS composition of the obtained carbons.

\begin{tabular}{cccccc}
\hline $\begin{array}{c}\text { Mass } \\
\text { Fraction (\%) }\end{array}$ & $C\left(B_{-} G l u\right)$ & $C\left(B_{-} G l u_{-} K\right)$ & $C\left(B_{-} G l u_{-} N\right)$ & $\begin{array}{c}C\left(B_{-} G l u \_P\right) \\
\text { I region }\end{array}$ & $\begin{array}{c}C\left(B \_G l u \_P\right) \\
\text { II region }\end{array}$ \\
\hline C & 83.39 & 65.42 & 74.75 & 75.26 & 87.02 \\
O & 9.76 & 19.05 & 15.40 & 12.92 & 8.72 \\
Na & 1.83 & 3.94 & 2.13 & 1.82 & 1.25 \\
Al & 0.16 & 4.38 & 1.18 & 0.22 & 0.16 \\
Si & 4.86 & 7.17 & 6.48 & 7.61 & 1.86 \\
K & - & 0.04 & - & - & - \\
N & - & - & 0.07 & - & - \\
P & - & - & - & 2.81 & 0.98 \\
\hline
\end{tabular}

Despite the apparently effective template removal evidenced by $\mathrm{X}$-ray diffraction and Raman, aluminum ( $\mathrm{Al}$ ) is detected in low concentrations. Some sodium $(\mathrm{Na})$ is also present and originated from the $\mathrm{NaOH}$ used for template dissolution. Additionally, silicium ( $\mathrm{Si}$ ), coming from the beaker where the dilution treatments were carried out, is noticed. The two 
regions with differentiated morphologies observed for the $C\left(B \_G l u \_P\right)$ sample also have different compositions.

Concerning the incorporation of doping elements, a homogeneous distribution of each heteroelement is detected. $\mathrm{K}$ is present in lower concentrations in the $C\left(B \_G l u \_K\right)$ sample due to its partial elimination during the washing process. Nevertheless, higher concentrations of $\mathrm{P}$ and $\mathrm{N}$ are detected in the $C\left(B_{-} G l{ }_{-} N\right)$ and $C\left(B \_G l u \_P\right)$ samples, respectively, indicating more effective doping. The mappings allow verifying that these elements are homogeneously distributed in the synthesized solids.

For all above, it is evident that boehmite is an adequate candidate to serve as a template for pristine or doped $(\mathrm{N}, \mathrm{P}, \mathrm{K})$ mesoporous carbon production by nanocasting. Boehmite is a cheap, easily available material with controlled mesoporosity. Although boehmite is transformed at higher temperatures in transitional aluminas, our paper demonstrates that pyrolysis temperatures up to $700{ }^{\circ} \mathrm{C}$ can be used without compromising the formation of mesoporous carbons. The proposed method is simple, low cost and very versatile, as the control and modification of the different synthetic parameters allows a large variety of carbon materials. The mesomicroporous character of the final carbon can be modulated by the modification of the textural properties of the starting boehmite and/or by changing the pyrolysis conditions. It is well reported that modifications of pyrolysis process parameters (temperature, heating ramp, number of heating steps, atmosphere flow and nature, residence time, etc.) and biomass activation (prior pyrolysis) with different chemical agents result in carbonaceous materials with different textural, chemical and surface properties [51-53]. In fact, one of the main advantages of the pyrolysis procedure is that it can be optimized according to the desired properties of the chars. Therefore, although fixed pyrolysis conditions are used in this paper, this possibility opens the range of properties of the obtained materials. The nature and properties of the produced carbons can also be tailored by changing the carbon precursor and the doping agent. Here, we used glucose as the residual biomass representative, but any carbon-containing molecule can be employed.

Additionally, our method is effective for the production of hybrid carbonaceous materials (without template removal). Again, the control of pyrolysis conditions (temperature, atmosphere, etc.), carbon source and dopant precursor could tailor the properties and nature of the hybrid. The use of $\mathrm{H}_{3} \mathrm{PO}_{4}$ as a $\mathrm{P}$ source is particularly interesting with the formation of a microporous crystalline $\mathrm{AlPO}_{4}-\mathrm{C}$ hybrid with an ordered microporous structure with potential catalytic properties.

\section{Materials and Methods}

\subsection{Mesoporous Boehmite Synthesis}

The sol-gel process was employed to produce mesoporous boehmite [54]. Aluminum isopropoxide, $\mathrm{Al}\left[\left(\mathrm{CH}_{3}\right)_{2} \mathrm{CHO}\right]_{3}$, dissolved in 2-propanol, was used as a precursor, and the process was catalyzed by ammonia. A $17 \mathrm{~g}$ amount of $\mathrm{Al}\left[\left(\mathrm{CH}_{3}\right)_{2} \mathrm{CHO}_{3}\right.$ (Sigma-Aldrich Merck KGaA, Darstadt, Germany), purity: >98\%) was mixed drop by drop with $170 \mathrm{~mL}$ of 2-propanol (Panreac Química S.L.U., Barcelona, Spain, 99.5\% pure) under continuous stirring. Then, the sample was refluxed at $105-110{ }^{\circ} \mathrm{C}$ for $5 \mathrm{~h}$ under constant stirring. After cooling to room temperature, a solution of $1.4 \mathrm{~mL}$ of $\mathrm{NH}_{3}$ (Panreac Química S.L.U., Barcelona, Spain), 30\% in $10 \mathrm{~mL}$ of deionized water was added dropwise to hydrolyze the alkoxide. Under these conditions, the mixture can gel rapidly. The resulting gel was dried in an oven at $85{ }^{\circ} \mathrm{C}$ for $2 \mathrm{~d}$ and finally calcined at $300^{\circ} \mathrm{C}$ for $2 \mathrm{~h}$ [55]. The XRD diagram (Figure S8) corroborates the formation of the boehmite structure (JCPDS: 00-049-0133), and its mesoporous character is confirmed by the $\mathrm{N}_{2}$ isotherms (Figure S9), with a BET surface area of $351 \mathrm{~m}^{2} / \mathrm{g}$, a mean pore diameter of $16.6 \mathrm{~nm}$ and a pore volume of $1.74 \mathrm{~cm}^{3} / \mathrm{g}$.

\subsection{Mesoporous Carbons Synthesis}

A $2.5 \mathrm{~g}$ amount of glucose (Sigma-Aldrich Merck KGaA, Darstadt, Germany, purity: $\geq 99.5 \%$ ) was dissolved in $4 \mathrm{~mL}$ of deionized water and added dropwise to $2 \mathrm{~g}$ of tem- 
plate, taking into account the total pore volume of the starting template (approximated to $2 \mathrm{~cm}^{3} / \mathrm{g}$ ). The obtained solid was dried in an oven at $100{ }^{\circ} \mathrm{C}$ for $16 \mathrm{~h}$.

To prepare the doped samples, three more impregnations were performed following the procedure described above, letting them dry in an oven at $100^{\circ} \mathrm{C}$ for $1 \mathrm{~h}$ and adding, dropwise, a sufficient amount per gram of the following doping agent solution to ensure that they had a relative influence in the structure and properties of the final solid: (a) $50 \mathrm{mg}$ of potassium hydroxide (KOH, Sigma-Aldrich Merck KGaA, Darstadt, Germany) purity $\geq 85 \%$ ) dissolved in $2 \mathrm{~mL}$ of deionized water; (b) $100 \mathrm{mg}$ of urea $\left(\mathrm{CH}_{4} \mathrm{~N}_{2} \mathrm{O}\right.$, Sigma-Aldrich Merck KGaA, Darstadt, Germany)) dissolved in $2 \mathrm{~mL}$ of deionized water; (c) $1 \mathrm{~mL}$ of phosphoric acid $\left(\mathrm{H}_{3} \mathrm{PO}_{4}\right.$, (Panreac Química S.L.U., Barcelona, Spain), 85\%) diluted in $1 \mathrm{~mL}$ of deionized water. The obtained solids were dried at $100^{\circ} \mathrm{C}$ for $16 \mathrm{~h}$.

Table 6 shows the used nomenclature for the prepared samples, and Figure 13 summarizes the appearance of the impregnated boehmite samples after drying. The color of the solid reflects a certain degradation (dehydration) degree of glucose as a result of the different compounds used in the impregnation and the thermal dryness treatment.

Table 6. Nomenclature of the synthesized samples.

\begin{tabular}{ccc}
\hline Additive & As prepared samples & Obtained carbons \\
\hline- & B_Glu & C(B_Glu) \\
KOH & B_Glu_K & C(B_Glu_K) \\
Urea & B_Glu_N & C(B_Glu_N) \\
$\mathrm{H}_{3} P \mathrm{PO}_{4}$ & B_Glu_P & C(B_Glu_P $)$ \\
\hline
\end{tabular}

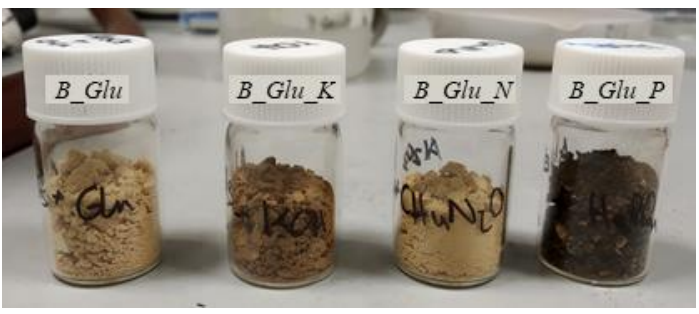

Figure 13. Samples of impregnated boehmite after drying at $100^{\circ} \mathrm{C}$ for $16 \mathrm{~h}$.

For pyrolysis, the impregnated templates were placed in a ceramic vessel within the controlled temperature zone of the horizontal oven. The pyrolysis process was carried out in two stages: (i) $5^{\circ} \mathrm{C} / \mathrm{min}$ until $200^{\circ} \mathrm{C}$, maintaining this temperature for $30 \mathrm{~min}$, and (ii) $10^{\circ} \mathrm{C} / \mathrm{min}$ until $700^{\circ} \mathrm{C}$, remaining for $1 \mathrm{~h}$ at this temperature. A constant $\mathrm{N}_{2}$ flow of $100 \mathrm{~mL} / \mathrm{min}$ was used during the treatment.

These pyrolysis conditions under an inert atmosphere were selected in order to assure the formation of nonactivated and nonmesoporous carbons. As reported, microporous carbons are generally produced under such conditions $[53,56]$. To demonstrate the decisive role of the boehmite template in producing mesoporous carbons, the utilization of pyrolysis atmosphere and conditions not forming mesoporous carbonaceous materials are mandatory.

\subsection{Template Removal}

Four consecutive dissolution steps were carried out to remove the template after pyrolysis, the first three steps with hot $4 \mathrm{M} \mathrm{NaOH}(\mathrm{NaOH}$ Panreac Química S.L.U., Barcelona, Spain, $\geq 85 \%$ ) and the last step with $1 \mathrm{M} \mathrm{NaOH}$ at room temperature. In the hot steps, the samples were mixed with $50 \mathrm{~mL}$ of solvent and left under agitation for 24,48 and $96 \mathrm{~h}$, respectively, as it was proved that the agitation time influenced the effectiveness of the dissolution process. After this, the mixtures were heated to $60^{\circ} \mathrm{C}$ for $1 \mathrm{~h}$ and filtered while still hot. In the last step, the mixtures were directly filtered after the agitation process. This template removal procedure was established from our previous studies on the effect of the $\mathrm{NaOH}$ concentration, 
time and temperature of treatment, on the dissolution of boehmite and alumina pure solids. Once filtered, the samples were subjected to several washings, an initial wash with a portion of the corresponding $\mathrm{NaOH}$ solvent and then with water up to neutral $\mathrm{pH}$. Finally, the resulting products were dried in an oven at $100{ }^{\circ} \mathrm{C}$ for $2 \mathrm{~h}$.

\subsection{Characterization Techniques}

Conventional XRD measurements were performed on an X'Pert Pro PANalytical diffractometer (Malvern Panalytical Ltd., Malvern, UK) equipped with a Cu anode and a graphite monochromator diffracted beam, working at $45 \mathrm{kV}$ and $40 \mathrm{~mA}$. Diffractograms were obtained in a continuous scan mode from 10 to $90^{\circ} 2 \theta$ using a $0.05^{\circ}$ step size and an acquisition time of $300 \mathrm{~s}$. For each diffraction pattern, structural determination was performed by comparison with the database PDF2 ICDD2000 (Powder Diffraction File 2 International Center for Diffraction Data, 2000), PA, USA).

From the XRD analysis, quantitative information of carbonaceous structure could be obtained following the approach of Alexander et al. [57]. According to these authors, based on the reduced intensity, several structural parameters are calculated: crystallite diameter along basal planes, which is the length of the crystalline domain in the plane (100) $\left(L_{a}\right)$; the average stacking height or length of the crystalline domain in the plane $(002)\left(L_{c}\right)$; the interlayer spacing $\left(d_{002}\right)$; and the $R$ value, defined as the ratio of the (002) peak intensity relative to the background at the same scattering angle. This parameter is related to the concentration of single graphene layers in a sample in such a way that the lower the $R$ value, the higher the concentration of single layers [58].

Bragg's equation was applied to calculate the interlayer spacing:

$$
d_{002}=\frac{\lambda}{2 \sin \theta_{002}}
$$

$L_{a}$ and $L_{c}$ parameters were calculated applying the Scherrer equation:

$$
\begin{aligned}
L_{c} & =\frac{K_{c} \lambda}{\beta_{002} \cos \theta_{002}} \\
L_{a} & =\frac{K_{a} \lambda}{\beta_{100} \cos \theta_{100}}
\end{aligned}
$$

where $\lambda$ corresponds to the X-ray wavelength used (1.18 $\AA$, copper $K \alpha), K$ is a dimensionless shape factor $\left(0.89\right.$ for the reflection $(002), K_{c}$, and 1.84 for the (100) one, $\left.K_{a}\right)$ [28], $\beta$ is the full width at half maximum (FWHM) of the considered diffraction peak and $\theta$ is the peak position.

Finally, the average number of aromatic layers per carbon crystallite $\left(\mathrm{N}_{\text {ave }}\right)$ has been also calculated as: $\left(L_{c} / \mathrm{d} 002\right)+1$.

The textural properties of synthesized solids were determined from the nitrogen adsorption-desorption isotherms obtained at $77 \mathrm{~K}$ using Micromeritics Tristar II equipment. (Micromeritics, Norcross, GA, USA). Prior to the measurement, samples were degassed under vacuum at $350{ }^{\circ} \mathrm{C}$ for $12 \mathrm{~h}$ using a vacuum degasser system 061 VacPrep of Micromeritics. Brunauer-Emmett-Teller (BET) method, t-plot and Barrett-Joyner-Halenda $(\mathrm{BJH})$ method were used to calculate the specific surface area, the micropore area and the pore size distribution.

Thermogravimetric analysis was performed using TA Instruments Q600 equipment (TA Instruments, New Castle, NC, USA). Samples were heated from room temperature to $900{ }^{\circ} \mathrm{C}$ with a heating rate of $10^{\circ} \mathrm{C} / \mathrm{min}$ under $100 \mathrm{~mL} / \mathrm{min}$ flow of pure synthetic air.

Raman spectroscopy measurements were carried out on an HR800 Horiba Jobin Yvon dispersive microscope with a 600 grooves/mm diffraction grating, using a green laser $(\lambda=532.14 \mathrm{~nm})$ working at $5 \mathrm{~mW}$ power, a $50 \times$ objective and a confocal aperture of 1000 microns. 
TEM micrographs were acquired with a FEI Talos electron microscope (Hillsboro, OR, USA) working at $200 \mathrm{kV}$ and equipped with a field emission filament. The compositional analyses of the samples were performed by energy dispersive X-Ray spectroscopy (EDS). For TEM preparation, a few milligrams of each sample was deposited directly on a 300mesh holey carbon-coated copper TEM grid.

Infrared spectra of the samples were collected in diffuse reflectance mode (DRIFTS) on a JASCO FT/IR-6200 6200 (JASCO International Co., Easton, MD, USA) unit to which a PIKE reflector accessory model EASI-DIFF was attached. The spectra were acquired on the pure samples (without dilution) in the range of 600 to $4000 \mathrm{~cm}^{-1}$ and with a resolution of 4 $\mathrm{cm}^{-1}$, accumulating 100 scans.

\section{Conclusions}

Boehmite is a very effective template to obtain mesoporous carbonaceous materials by the nanocasting method. The incorporation of different doping agents during the synthetic process is also satisfactory, resulting in a homogeneous distribution of the doping element. Nevertheless, the K doping procedure results in a lower doping element concentration in comparison to the rest of the doped carbons.

Doping with $\mathrm{KOH}$ and urea insignificantly modifies the textural properties of the resulting carbon. However, the use of $\mathrm{H}_{3} \mathrm{PO}_{4}$ as a dopant leads to a chemical reaction with the boehmite template and the formation of $\mathrm{AlPO}_{4}$, an indirect template, resulting in solids with lower specific surface values and a higher percentage of microporosity. This fact clearly demonstrates the significant influence of the used template on the textural properties of the final carbon.

All doped carbons show better thermal resistance than the undoped carbons, particularly the P-doped sample, with a combustion temperature $120^{\circ} \mathrm{C}$ higher than the rest of the samples.

The described process is an effective, easy, versatile and economical method to obtain mesoporous carbons from renewable biomass sources.

Supplementary Materials: The following are available online at https:/ /www.mdpi.com/article/10 .3390/catal11091132/s1, Figure S1: Evolution of X-ray diffractograms of pyrolyzed B_Glu_K sample after each stage of template dissolution ( ${ }^{*}$ silicate), Figure S2: Evolution of X-ray diffractograms of pyrolyzed $B \_G l u \_N$ sample after each stage of template dissolution ( ${ }^{*}$ silicate), Figure S3: Thermal analysis for samples $B \_G l u \_K$ (after the first template dissolution step) and $C\left(B \_G l u \_K\right)$, Figure S4: Thermal analysis for samples $B \_G l u \_N$ (after the first template dissolution step) and $C\left(B \_G l u \_N\right)$, Figure S5: Thermal analysis for samples $B_{-} G l u_{-} P$ (after the first template dissolution step) and $C\left(B \_G l u \_P\right)$, Figure S6: Mapping for $C\left(B \_G l u\right)$, Figure S7: Mapping for $C\left(B \_G l u \_N\right)$, Figure S8: Diffractogram of the synthesized boehmite, Figure S9: N2 isotherms of the synthesized boehmite.

Author Contributions: Conceptualization, M.Á.C.; methodology, M.I.D.; validation, M.I.D.; formal analysis, S.I.; investigation, M.O.-F.; resources, M.Á.C. and S.I..; data curation, S.I.; writing-original draft preparation, M.O.-F., S.I. and M.I.D.; writing-review and editing, M.Á.C.; visualization, M.Á.C.; supervision, M.Á.C.; project administration, M.Á.C.; funding acquisition, M.Á.C. and S.I. All authors have read and agreed to the published version of the manuscript.

Funding: This research was funded by the Spanish Ministry of Economy and Competitiveness (MINECO), (ENE2017-82451-C3-3-R) cofinanced by European Union ERDF funds.

Data Availability Statement: All data are available within the paper and Supplementary Materials.

Conflicts of Interest: The authors declare no conflict of interest.

\section{References}

1. Milazzo, G. IUPA C-Manual of Symbols and Terminology for Physico-chemical Quantities and Units. J. Electroanal. Chem. Interfacial Electrochem. 2006, 128, 285-286. [CrossRef]

2. Lu, A.H.; Schüth, F. Nanocasting: A Versatile Strategy for Creating Nanostructured Porous Materials; Royal Society of Chemistry: London, UK, 2006. 
3. Inagaki, M.; Toyoda, M.; Soneda, Y.; Tsujimura, S.; Morishita, T. Templated mesoporous carbons: Synthesis and applications. Carbon 2016, 107, 448-473. [CrossRef]

4. Dhawane, S.H.; Kumar, Y.; Halder, G. Recent advancement and prospective of heterogeneous carbonaceous catalysts in chemical and enzymatic transformation of biodiesel. Energy Convers. Manag. 2018, 167, 176-202. [CrossRef]

5. Lee, J.; Kim, J.; Hyeon, T. Recent progress in the synthesis of porous carbon materials. Adv. Mater. 2006, 18-16, 2073-2094. [CrossRef]

6. Liang, C.; Li, Z.; Dai, S. Mesoporous carbon materials: Synthesis and modification. Angew. Chemie-Int. Ed. 2008, 47, 3696-3717. [CrossRef] [PubMed]

7. Bauer, J.; Schroer, A.; Schwaiger, R.; Kraft, O. Approaching theoretical strength in glassy carbon nanolattices. Nat. Mater. 2016, 15, 438-443. [CrossRef]

8. Zhang, X.; Zhong, L.; Mateos, A.; Kudo, A.; Vyatskikh, A.; Gao, H.; Greer, J.R.; Li, X. Theoretical strength and rubber-like behaviour in micro-sized pyrolytic carbon. Nat. Nanotechnol. 2019, 14, 762-769. [CrossRef] [PubMed]

9. Crook, C.; Bauer, J.; Guell, A.; Santos de Oliveira, C.; Martins de Sousa, J.; Berger, J.B.; Valdevit, L. Plate-nanolattices at the theoretical limit of stiffness and strength. Nat. Commun. 2020, 11, 1579. [CrossRef]

10. Enterría, M.; Figueiredo, J.L. Nanostructured mesoporous carbons: Tuning texture and surface chemistry. Carbon 2016, 108, 79-102. [CrossRef]

11. Zhong, R.; Sels, B.F. Sulfonated mesoporous carbon and silica-carbon nanocomposites for biomass conversion. Appl. Catal. B Environ. 2018, 236, 518-545. [CrossRef]

12. Alegre, C.; Sebastián, D.; Gálvez, M.E.; Moliner, R.; Lázaro, M.J. Sulfurized carbon xerogels as Pt support with enhanced activity for fuel cell applications. Appl. Catal. B Environ. 2016, 192, 260-267. [CrossRef]

13. Alegre, C.; Sebastián, D.; Gálvez, M.E.; Baquedano, E.; Moliner, R.; Aricò, A.S.; Baglio, V.; Lázaro, M.J. N-doped carbon xerogels as Pt support for the electro-reduction of oxygen. Materials 2017, 10, 1092. [CrossRef]

14. Song, Y.; Liu, G.; Yuan, Z.Y. N-, P- and B-doped mesoporous carbons for direct dehydrogenation of propane. RSC Adv. 2016, 6, 94636-94642. [CrossRef]

15. Chen, C.; Zhang, J.; Zhang, B.; Yu, C.; Peng, F.; Su, D. Revealing the enhanced catalytic activity of nitrogen-doped carbon nanotubes for oxidative dehydrogenation of propane. Chem. Commun. 2013, 49, 8151-8153. [CrossRef]

16. Mao, S.; Li, B.; Su, D. The first principles studies on the reaction pathway of the oxidative dehydrogenation of ethane on the undoped and doped carbon catalyst. J. Mater. Chem. A. 2014, 2, 5287-5294. [CrossRef]

17. Gotoh, Y.; Tamada, K.; Akuzawa, N.; Fujishige, M.; Takeuchi, K.; Endo, M.; Matsumoto, R.; Soneda, Y.; Takeichi, T. Preparation of air-stable and highly conductive potassium-intercalated graphite sheet. J. Phys. Chem. Solids 2013, 74, 1482-1486. [CrossRef]

18. Liu, K.; Zhang, J.; Ding, R.; Zheng, X.; Yang, T.; Wang, C.; Chen, M. Potassium-assisted carbonization of pyrrole to prepare nanorod-structured graphitic carbon with a high surface area for high-rate supercapacitors. Carbon 2019, 155, 326-333. [CrossRef]

19. Wei, Z.; Wang, J.; Sun, J.; Zhang, Z.; Lu, B.; Guo, J. Thermal puffing promoting the synthesis of N-doped hierarchical porous carbon-CoOx composites for alkaline water reduction. ACS Omega 2021, 6, 6474-6481. [CrossRef]

20. Yan, X.-L.; Li, H.-F.; Wang, C.; Jiang, B.-B.; Hu, H.-Y.; Xie, N.; Wu, M.H.; Vinodgopal, K.; Dai, G.P. Melamine as a single source for fabrication of mesoscopic 3D composites of N-doped carbon nanotubes on graphene. RSC Adv. 2018, 8, 12157. [CrossRef]

21. Li, D.; Chen, W.; Wu, J.; Jia, C.Q.; Jiang, X. The preparation of waste biomass-derived N- doped carbons and their application in acid gas removal: Focus on $\mathrm{N}$ functional groups. J. Mater. Chem. A 2020, 8, 24977. [CrossRef]

22. Zhang, X.; Cui, W.; Page, K.L.; Pearce, C.I.; Bowden, M.E.; Graham, T.R.; Shen, Z.; Li, P.; Wang, Z.; Kerisit, S.; et al. Size and morphology controlled synthesis of boehmite nanoplates and crystal growth mechanisms. Cryst. Growth Des. 2018, 18, 3596-3606. [CrossRef]

23. Takagaki, A.; Jung, J.C.; Hayashi, S. Solid Lewis acidity of boehmite $\gamma-\mathrm{AlO}(\mathrm{OH})$ and its catalytic activity for transformation of sugars in water. RSC Adv. 2014, 4, 43785-43791. [CrossRef]

24. Bokhimi, X.; Toledo-Antonio, J.A.; Guzman-Castillo, M.L.; Hernandez-Beltran, F. Relationship between crystallite size and bond lengths in boehmite. J. Solid State Chem. 2001, 159, 32-40. [CrossRef]

25. Shirai, T.; Watanabe, H.; Fuji, M.; Takahashi, M. Structural properties and surface characteristics on aluminum oxide powders. Annu. Rep. Ceram. Res. Lab. Nagoya Inst. Technol. 2009, 9, 23-31.

26. Samain, L.; Jaworski, A.; Edén, M.; Ladd, D.M.; Seo, D.K.; García-García, F.J.; Häussermann, U. Structural analysis of highly porous $\gamma-\mathrm{Al}_{2} \mathrm{O}_{3}$. J. Solid State Chem. 2014, 217, 1-8. [CrossRef]

27. $\mathrm{Gu}, \mathrm{J}$; Wang, J.; Leszczynski, J. Structure and energetics of (111) surface of $\gamma-\mathrm{Al}_{2} \mathrm{O}_{3}$ : Insights from DFT including periodic boundary approach. ACS Omega 2018, 3, 1881-1888. [CrossRef]

28. Liang, Y.; Feng, X.; Zhi, L.; Kolb, U.; Müllen, K. A simple approach towards one-dimensional mesoporous carbon with superior electrochemical capacitive activity. Chem. Commun. 2009, 7, 809-811. [CrossRef]

29. Zhao, G.; He, J.; Zhang, C.; Zhou, J.; Chen, X.; Wang, T. Highly dispersed Pt nanoparticles on mesoporous carbon nanofibers prepared by two templates. J. Phys. Chem. C 2008, 112, 1028-1033. [CrossRef]

30. Mezni, A.; Altalhi, T.; Ben Saber, N.; Aldalbahi, A.; Boulehmi, S.; Santos, A.; Losic, D. Size- and shape-controlled synthesis of well-organised carbon nanotubes using nanoporous anodic alumina with different pore diameters. J. Colloid Interface Sci. 2017, 491, 375-389. [CrossRef] 
31. Gallo, J.M.R.; Trapp, M.A. The chemical conversion of biomass-derived saccharides: An overview. J. Braz. Chem. Soc. 2017, 28, 1586-1607. [CrossRef]

32. Sharma, V.T.; Halanur, M.; Kamath, S.V.; Mondal, D.; Kotrappanavar, N.S. Fe-Al based nanocomposite reinforced hydrothermal carbon: Efficient and robust absorbent for anionic dyes. Chemosphere 2020, 259, 127421. [CrossRef] [PubMed]

33. Sun, F.; Qu, Z.; Wang, H.; Liu, X.; Pei, T.; Han, R.; Gao, J.; Zhao, G.; Lu, Y. Vapor deposition of aluminium oxide into N-rich mesoporous carbon framework as a reversible sulfur host for lithium-sulfur battery cathode. Nano Research 2021, 14, 131-138. [CrossRef]

34. Yin, Y.; Zhang, J.; Sheng, C. Effect of pyrolysis temperature on the char micro-structure and reactivity of NO reduction. Korean J. Chem. Eng. 2009, 26, 895. [CrossRef]

35. Collins, J.; Zheng, D.; Ngo, T.; Qu, D.; Foster, M. Partial graphitization of activated carbon by surface acidification. Carbon 2014, 79, 500-517. [CrossRef]

36. Xin, S.; Yang, H.; Chen, Y.; Yanga, M.; Chena, L.; Wanga, X.; Chena, H. Chemical structure evolution of char during the pyrolysis of cellulose. J. Anal. Appl Pyrolysis 2015, 116, 263-271. [CrossRef]

37. Li, Z.Q.; Lu, C.J.; Xia, Z.P.; Zhou, Y.; Luo, Z. X-ray diffraction patterns of graphite and turbostratic carbon. Carbon 2007, 45, 1686-1695. [CrossRef]

38. Rodríguez, N.; Agamez-Pertuz, Y.Y.; Romero, E.; Díaz-Velásquez, J.J.; Odriozola, J.A.; Centeno, M.A. Effect of starch as binder in carbon aerogel and carbon xerogel preparation. J. Non-Cryst. Solids 2019, 522, 119554. [CrossRef]

39. Thommes, M.; Kaneko, K.; Neimark, A.V.; Olivier, J.P.; Rodríguez-Reinoso, F.; Rouquerol, J.; Sing, K.S.V. Physisorption of gases, with special reference to the evaluation of surface area and pore size distribution (IUPAC technical report). Pure Applied Chem. 2015, 87, 1051-1069. [CrossRef]

40. Leofanti, G.; Padovan, M.; Tozzola, G.; Venturelli, B. Surface area and pore texture of catalysts. Catal. Today 1998, 41, 207-219. [CrossRef]

41. Liu, B.; Liu, L.; Yu, Y.; Zhang, Y.; Chen, A. Synthesis of mesoporous carbon with tunable pore size for supercapacitors. New J. Chem. 2020, 44, 1036. [CrossRef]

42. Liu, B.; Yang, M.; Chen, H.B.; Liu, Y.J.; Yang, D.G.; Li, H.M. Graphene-like porous carbon nanosheets derived from salvia splendens for high-rate performance supercapacitors. J. Power Sources 2018, 397, 1-10. [CrossRef]

43. Ansari, H.; Joss, L.; Hwang, J.; Martin Trusler, J.P.; Maitland, G.; Pini, R. Supercritical adsorption in micro- and meso-porous carbons and its utilization for textural characterization. Micropor. Mesopor. Mat. 2020, 308, 110537. [CrossRef]

44. Saygilı, H.; Güzel, F. High surface area mesoporous activated carbon from tomato processing solid waste by zinc chloride activation: Process optimization, characterization and dyes adsorption. J. Clean. Prod. 2016, 113, 995-1004. [CrossRef]

45. Santos, J.L.; Megias-Sayago, C.; Ivanova, S.; Centeno, M.A.; Odriozola, J.A. Functionalized biochars as supports for Pd/C catalysts for efficient hydrogen production from formic acid. Appl. Catal. B Environ. 2021, 282, 119615. [CrossRef]

46. Liu, H.; Zhang, Y.; Li, R.; Sun, X.; Abou-Rachid, H. Thermal and chemical durability of nitrogen-doped carbon nanotubes. J. Nanopart Res. 2012, 14, 1016. [CrossRef]

47. Liu, H.; Zhang, Y.; Li, R.; Sun, X.; Désilets, S.; Abou-Rachid, H.; Jaidann, M.; Lussier, L.S. Structural and morphological control. nitrogen incorporation and stability of aligned nitrogen-doped carbon nanotubes. Carbon 2010, 48, 1498-1507. [CrossRef]

48. Ferrari, A.C.; Robertson, J. Interpretation of Raman spectra of disordered and amorphous carbon. Phys. Rev. B Condens. Matter. 2000, 61, 14095-14107. [CrossRef]

49. Kouketsu, Y.; Mizukami, T.; Mori, H.; Endo, S.; Aoya, M.; Hara, H.; Nakamura, D.; Wallis, S. A new approach to develop the Raman carbonaceous material geothermometer for low-grade metamorphism using peak width. Island Arc. 2014, $23,33-50$. [CrossRef]

50. Centeno, M.A.; Grange, P. Platinum aluminophosphate oxynitride (Pt-AlPON) catalysts. Consequences of surface hydrolysis and heating processes on the structure. J. Phys. Chem. B 1999, 103, 2431-2438. [CrossRef]

51. Tripathi, M.; Sahu, J.N.; Ganesan, P. Effect of process parameters on production of biochar from biomass waste through pyrolysis: A review. Renew. Sust. Energ. Rev. 2016, 55, 467-481. [CrossRef]

52. Jafri, N.; Wong, W.Y.; Doshi, V.; Yoon, L.W.; Cheah, K.H. A review on production and characterization of biochars for application in direct carbon fuel cells. Process. Saf. Environ. Prot. 2018, 118, 152-166. [CrossRef]

53. Santos, J.L.; Centeno, M.A.; Odriozola, J.A. Reductant atmospheres during slow pyrolysis of cellulose: First approach to obtaining efficient char-based catalysts in one po. J. Anal. Appl. Pyrolysis 2020, 148, 104821. [CrossRef]

54. González, R.D.; López, T.; Gómez, R. Sol-Gel preparation of supported metal catalysts. Catal. Today 1997, 35, 293-317. [CrossRef]

55. Centeno, M.A.; Portales, C.; Carrizosa, I.; Odriozola, J.A. Gold supported $\mathrm{CeO}_{2} / \mathrm{Al}_{2} \mathrm{O}_{3}$ catalysts for $\mathrm{CO}$ oxidation: Influence of the ceria phase. Catal. Lett. 2005, 102, 289-297. [CrossRef]

56. Du, S.; Valla, J.A.; Bollas, G.M. Characteristics and origin of char and coke from fast and slow, catalytic and thermal pyrolysis of biomass and relevant model compounds. Green Chem. 2013, 15, 3214-3229. [CrossRef]

57. Alexander, L.E.; Sommer, E.C. Systematic analysis of carbon black structures. J. Phys. Chem. 1956, 60, 1646-1649. [CrossRef]

58. Okolo, G.N.; Neomagus, W.J.P.; Everson, C.; Roberts, J.; Bunt, R.; Sakurovs, R.; Mathews, P. Chemical-structural properties of South African bituminous coals: Insights from wide angle XRD-carbon fraction analysis, ATR-FTIR, solid state 13C NMR, and HRTEM techniques. Fuel 2015, 158, 779-792. [CrossRef] 